
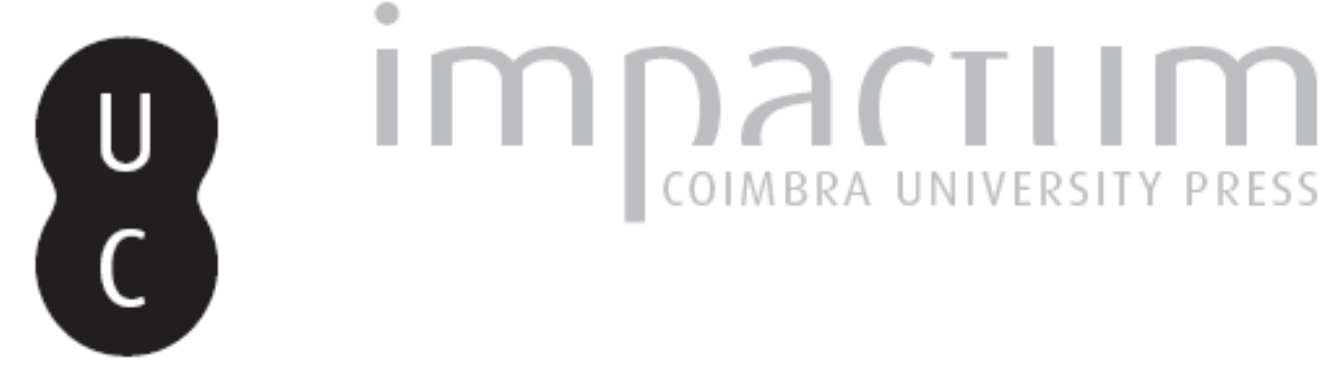

\title{
[Recensão a] JEAN-FABRICE NARDELLI, Le motif de la paire d'amis héroïque à prolongements homophiles: perspectives odysséennes et proche-orientales
}

Autor(es): $\quad$ Rodrigues, Nuno Simões

Publicado por: Centro de História da Universidade de Lisboa

URL

persistente:

URI:http://hdl.handle.net/10316.2/35010

DOI:

DOI:http://dx.doi.org/10.14195/0871-9527_23_19

Accessed : $\quad$ 26-Apr-2023 09:21:03

A navegação consulta e descarregamento dos títulos inseridos nas Bibliotecas Digitais UC Digitalis, UC Pombalina e UC Impactum, pressupõem a aceitação plena e sem reservas dos Termos e Condições de Uso destas Bibliotecas Digitais, disponíveis em https://digitalis.uc.pt/pt-pt/termos.

Conforme exposto nos referidos Termos e Condições de Uso, o descarregamento de títulos de acesso restrito requer uma licença válida de autorização devendo o utilizador aceder ao(s) documento(s) a partir de um endereço de IP da instituição detentora da supramencionada licença.

Ao utilizador é apenas permitido o descarregamento para uso pessoal, pelo que o emprego do(s) título(s) descarregado(s) para outro fim, designadamente comercial, carece de autorização do respetivo autor ou editor da obra.

Na medida em que todas as obras da UC Digitalis se encontram protegidas pelo Código do Direito de Autor e Direitos Conexos e demais legislação aplicável, toda a cópia, parcial ou total, deste documento, nos casos em que é legalmente admitida, deverá conter ou fazer-se acompanhar por este aviso.

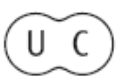



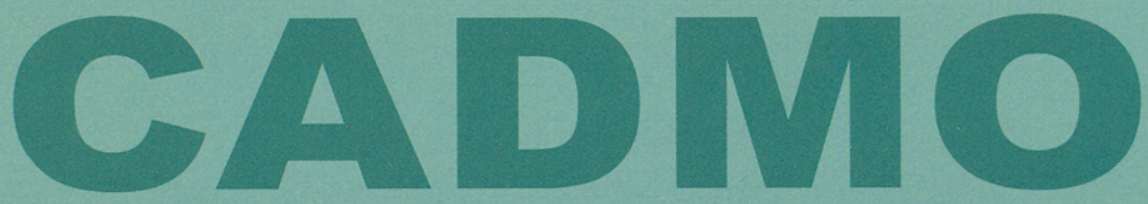

Revista de História Antiga

\author{
Centro de História \\ da Universidade de Lisboa
}

\title{
23
}

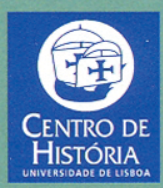

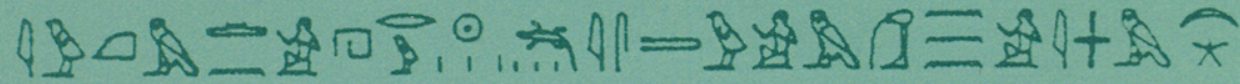

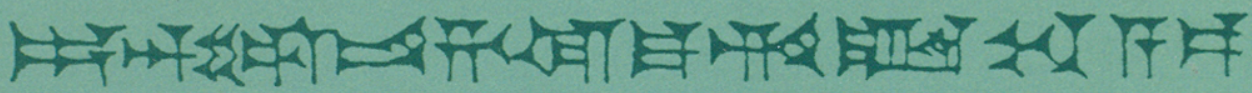
MHNIN AEI $\triangle \mathrm{E} \Theta \mathrm{EA}$ ПH$\Lambda \mathrm{HIA} \triangle \mathrm{E} \Omega$ 
O III bloco concentra-se nas formas de praticar a religião e de representar o pensamento religioso. Ritos, sacrifícios, jogos, procissões, formulação de orações, cânticos e hinos são aqui discutidos ao pormenor com um excelente uso das fontes de que dispomos para o fazer.

$\mathrm{Na}$ IV parte, são os agentes religiosos que ganham destaque. Com efeito, seria difícil fazermos qualquer estudo da religiosidade romana sem levar em conta aqueles que a protagonizaram e lhe deram existência. Assim, estudam-se aqui os papéis de sacerdotes, aristocratas, imperadores, elites urbanas, de todos aqueles que marcaram a definição da religião entre os Romanos.

Os problemas em torno da alteridade religiosa estão tratados nas partes $\mathrm{V}$ e VI. No quadro da religiosidade da Roma Antiga e do Império Romano, impõe-se o tratamento das problemáticas das religiões dos Outros, em particular daquelas que efectivamente marcaram a diferença na construção da Romanitas, como o judaísmo, o cristianismo e o mitraísmo. Estas são, evidentemente, religiões orientais e de mistérios, sendo porém de notar que se tenta definir, e bem, o que de novo ou de romano tem essa orientalidade; não deixa, porém, de ser uma raiz oriental que está aqui em causa. Por outro lado, é de assinalar aquilo que Roma exportou no que diz respeito à espiritualidade e à religiosidade, designadamente para o Oriente.

Trata-se, por conseguinte, de mais um excelente exemplo da qualidade que a Blackwell tem vindo a construir no domínio dos manuais académico-científicos. Este «Companion» é mais um excelente instrumento de trabalho para os estudiosos da Antiguidade Clássica e deve marcar presença em todas as boas bibliotecas dedicadas ao assunto. A obra reúne os contributos de 31 autores, alguns deles especialistas reconhecidos nos seus campos de estudo, dos quais destacamos o incontornável K. Galinsky, reconhecido especialista no período augustano. Seria de esperar, porém, uma maior presença de autores italianos ou espanhóis, que muito têm escrito sobre estas problemáticas.

O livro inclui uma extensa bibliografia, glossário, mapas, figuras, respectivas legendas e índices geral, antroponímico e toponímico.

\section{Nuno Simões Rodrigues}

JEAN-FABRICE NARDELLI, Le motif de la paire d'amis héroïque à prolongements homophiles: perspectives odysséennes et proche-orientales, Amsterdam, Adolf M. Hakkert Publisher, 2004, 297 pp. ISBN - 90-256-0638-5 
JEAN-FABRICE NARDELLI, Homosexuality and Liminality in the Gilgameš and Samuel, Amsterdam, Adolf M. Hakkert Publisher, 2007, 106 pp. ISBN - 90-256-1226-1

A recente produção televisiva da Starz, Spartacus (2010-2013), apesar de se basear sobretudo em fontes históricas tidas pelos investigadores como fidedignas, não resiste à tentação de integrar no enredo elementos ficcionais, à boa maneira do romance histórico oitocentista de que a adaptação cinematográfica é herdeira. Entre esses elementos, salientamos a construção das personagens de Agron (Dan Feuerriegel) e de Nazir (Pana Hema-Taylor), que, no contexto da célebre rebelião de escravos, evocam o tema do «par de amigos heróico", tal como o conhecemos desde a Antiguidade e que subjaze a este livro.

Apesar de este ser um tema sobretudo reconhecido na literatura greco-romana e em ambiente ficcional (o que não exclui a presença de informações relativas a «factos» tidos como históricos, como são os casos de Aristogíton e Harmódio, mencionado por Tucídides, e de Alcibíades, sobretudo testemunhado por Plutarco), de que são exemplos as narrativas em torno de Aquiles e Pátroclo, Teseu e Pirítoo, Héracles e Hilas, Orestes e Pílades e Niso e Euríalo, o facto é que, como muito bem demonstra Nardelli, o tema remontava a uma estrutura mais antiga, especificamente a anteriores contextos próximo-orientais.

Assim, não esquecendo a forte componente grega da problemática, que todavia Nardelli opta por analisar no primeiro destes dois volumes a partir de um «casal» menos conhecido - Telémaco e Pisístrato -, parte substancial deste estudo centra-se nas narrativas em torno de David e Jónatas, que nos chegaram através dos textos bíblicos, sem esquecer as figuras mesopotâmicas de Gilgamesh e Enkidu. Foi, aliás, a pertinência do tema que levou o A., já depois de ter publicado o volume citado em primeiro lugar, a publicar o segundo, desta vez em inglês, centrando-se agora essencialmente no controverso (uma vez que inclui a problemática bíblica) mundo próximo-oriental, não esquecendo o contexto egípcio do mesmo.

É evidente que o tema não é original e muita já se escreveu sobre o assunto (e.g. o extenso estudo de B. Sergent, para o caso o mundo grego, ou os de K. Stone, T. Horner e M. Nissinen para o universo bíblico). A novidade estará, eventualmente, no método comparativo adoptado pelo A., que olha sempre em confronto as fontes próximo-orientais e gregas, a que se alia o assinalável rigor filológico, patente sobretudo no recurso às línguas antigas (acádico, egípcio, hebraico e, claro, o grego), que se confirmam indispensáveis e incontornáveis para um estudo desta natureza. Além desta opção 
metodológica, não podemos deixar de aplaudir a perspectiva abrangente, o olhar globalizante, que toma as ditas "civilizações pré-clássicas» e as ditas «civilizações clássicas» como um todo de fronteiras ténues, essencialmente mediterrâneas, que conviveram no espaço e no tempo, em determinadas circunstâncias, e que, por isso mesmo, não deixaram de interagir e de se interinfluenciar. Trata-se efectivamente de um método a reconhecer como válido e que vem no seguimento de outros autores e investigações, como por exemplo as de M. L. West.

Menos positiva é a opção de apresentar, no primeiro caso, como bibliografia final apenas uma lista complementar aos estudos que vão sendo citados ao longo do volume. Seria muito mais prático para o investigador/ leitor que vier a recorrer a este livro encontrar uma listagem final completa, como toda a informação referida. No segundo volume, nem sequer existe essa tão necessária listagem. Os índices, pelo contrário, são pormenorizados e da maior utilidade em ambos os livros.

\section{Nuno Simões Rodrigues}

MARCO FANTUZZI, Achilles in Love. Intertextual Studies, Oxford: Oxford University Press, 2012, 317 pp. ISBN 978-0-19-960362-6

O problema das relações amorosas de Aquiles parece ter sido um dos que, praticamente desde a Antiguidade, parecem ter preocupado os vários autores que a ele se dedicaram. Bastará recordar que, na origem da llíada, está uma disputa de natureza amorosa, que parece condicionar todo o desenvolvimento do poema e determinar mesmo o destino das personagens centrais. Com efeito, não fosse a ira de Aquiles desencadeada pela perda de Briseide, e provavelmente nem Heitor nem Pátroclo teriam tido o fim que acabaram por ter.

O livro agora publicado por M. Fantuzzi regressa ao problema dos amores de Aquiles e, recorrendo à intertextualidade como metodologia essencial, analisa o «percurso biográfico» da personagem, a partir do prisma das relações amorosas que são tidas como «as paixões aquilinas»: Deidamia, Briseide, Pentesileia e, como não poderia deixar de ser, Pátroclo. Este é, aliás, um dos principais motivos de interesse do volume. Pois se, quer a partir da epopeia, quer a partir da tragédia, sobretudo, as paixões amorosas de Aquiles por aquelas três figuras femininas parecem ser mais ou menos consensuais (no caso de Deidamia as fontes são todavia mais díspares e no de Pentesileia mais abrangentes), no que diz respeito à «relação amorosa» com Pátroclo, o consenso é menos difícil de obter. Com efeito, desde a Antiguidade que os exegetas, comentadores e 